\title{
UNIVERSAL SCREENING FOR GESTATIONAL DIABETES MELLITUS IN ANTENATAL MOTHERS IMPROVES ANTENATAL MANAGEMENT AND OUTCOMES - SINGLE CENTRE EXPERIENCE
}

\author{
Nicholas Lee Wen Sheng1, Daniel Wong Bang Lung², Safurah Jaafar ${ }^{3}$, Sangeetha Shyam ${ }^{4}$, Tiffany \\ Grace Wong ${ }^{5}$ and Salmiah Sharif 6 \\ ${ }^{1}$ School of Medicine, University of Tasmania, Level 1, Medical Science 1, 17 Liverpool St, Hobart TAS 7000, Australia. \\ 2 School of Medicine, International Medical University, 126, Jalan Jalil Perkasa 19, Bukit Jalil, 57000 Kuala Lumpur, \\ Federal Territory of Kuala Lumpur, Malaysia. \\ ${ }^{3}$ Community Medicine, International Medical University, 126, Jalan Jalil Perkasa 19, Bukit Jalil, 57000 Kuala Lumpur, \\ Federal Territory of Kuala Lumpur, Malaysia. \\ ${ }^{4}$ Division of Nutrition \& Dietetics, School of Health Sciences, International Medical University, and, Centre for \\ Translational Research, IMU Institute for Research, Development, and Innovations (IRDI), International Medical \\ University 126, Jalan Jalil Perkasa 19, Bukit Jalil, 57000 Kuala Lumpur, Federal Territory of Kuala Lumpur, Malaysia. \\ ${ }^{5}$ School of Medicine, University of Glasgow, University Avenue, Glasgow G12 8QQ. United Kingdom. \\ 6 Seremban Health Clinic, Jalan Rasah, Bukit Rasah, 70300 Seremban, Negeri Sembilan, Malaysia.
}

\section{Corresponding author: Safurah Jaafar}

Email: safurahjaafar@imu.edu.my

\begin{abstract}
This study examined the impact of universal screening in diagnosing and managing gestational diabetes (GDM) amongst antenatal mother and associated neonatal outcomes. It is a single-centre, retrospective study on routinely collected data of antenatal women in Health Clinic Seremban over one year in 2018. All women diagnosed with GDM, who were not known sufferers of type 1 or type 2 diabetes were included in this study. Participants were stratified according to risk factors for GDM to compare the performance of a selective high-risk screening approach to that of universal screening for detecting GDM. Subjects were categorized as high-risk for GDM based on the guidelines recommended by the Malaysian Clinical Practice guidelines. It was found that through universal screening, 246 antenatal mothers were tested positive for GDM out of the 987 of these mothers without prior diabetes, giving a prevalence of $24.9 \%$. If selective screening using traditional risk factors had been employed, 54 (22\%) of the antenatal mothers diagnosed with GDM would have been missed. It was established that risk factors for GDM included advancing age, other ethnicities (patients that are not of Malay, Chinese nor Indian ethnicities), obesity, history of abortion or GDM and family history of diabetes mellitus. Neonatal outcomes of those with GDM as compared to those without were similar. This study highlights that universal screening improved GDM detection rates amongst antenatal mothers. The increased detection helped facilitate an earlier intervention which may have contributed to better antenatal management and outcomes for neonates and their mothers.
\end{abstract}

Keywords: Universal screening, selective screening, gestational diabetes mellitus, antenatal mothers

\section{INTRODUCTION}

Gestational diabetes mellitus (GDM) is the temporary occurrence of high blood sugar levels during pregnancy due to impaired insulin action. The International Diabetes Federation 2017 estimated that 1 in 7 births was affected by GDM¹. Although GDM typically resolves after pregnancy, it carries significant maternal and foetal implications. For the infants there are increased risk of miscarriage, congenital malformations, foetal macrosomia ${ }^{2}$ and a higher risk of obesity and T2DM during their lifetimes ${ }^{3}$. In addition, there is also a higher risk of developing Type 2 Diabetes Mellitus amongst antenatal mothers with GDM. These increasing risks pose as a public health concern in Malaysia.
Criteria to diagnose GDM have evolved over time. The Hyperglycaemia and Adverse Pregnancy Outcomes (HAPO study) involving 25,505 pregnant women from nine countries showed associations of maternal glucose with increased birth weight and other adverse pregnancy outcomes ${ }^{4}$. Taking this landmark finding into consideration, the International Association of Diabetes in Pregnancy Study Groups (IADPSG) recommended that GDM be diagnosed based on fasting plasma glucose or, 1 or $2 \mathrm{hr}$ plasma glucose post a $75 \mathrm{~g}$ oral glucose tolerance test. Elevation in one of these criteria is considered sufficient to diagnose GDM. It is well recognised that the newer criteria if adopted would lead to 
an increased diagnosis of GDM requiring more healthcare investment ${ }^{5}$.

Although there is no exact sugar value that is considered safe in pregnancy, the Malaysian Clinical Practice Guidelines on the Management of Diabetes in Pregnancy issued in 2017 is the reference standard for the screening and management of $\mathrm{GDM}^{6}$ adopted from various local and international references. Attending providers are ultimately responsible for the management of their patients.

This debate on diagnostic criteria has also been paralleled by another debate about whether screening for GDM in pregnant women should be selective; that is screening only those with risk factors, or universal which is screening all pregnancies. Initial reviews, such as by Carr et al, have found that universal screening is less cost-effective than selective screening ${ }^{7}$.

In recent years, several studies are reconsidering stratification of screening to identify those with greater risk. While these suggestions may seem attractive, it is more economical to consider universal screening in populations with a high prevalence of any individual risk factor rather than selective screening ${ }^{8-10}$.It is worth the extraeconomic cost especially during a time when diabetes mellitus is becoming increasingly prevalent in Malaysia.

Screening and detection of GDM allows early and active intervention in pregnancy, which significantly improves pregnancy outcomes. Malaysia currently adopts a national selective risk-based screening for $\mathrm{GDM}^{12}$, although recommendations from the World Health Organization, International Federation of Gynaecology and Obstetrics ${ }^{11}$ are for universal screening especially among the high-risk population.

As selective screening is less sensitive than universal screening in the detection of GDM in the population $^{12}$, it can be inferred that the reports generated at the service level are underestimating the actual prevalence of GDM. Given the importance of early screening and treatment of GDM, a few clinical centres in Malaysia have started using universal screening as a pilot implementation strategy. Since there is insufficient information on justification for universal screening for GDM in Malaysia, we evaluated the risk factors for GDM amongst women attending a clinic that implemented this universal screening strategy. We estimated the number of GDM cases that would be missed if routine selective screening was employed. We also evaluated the maternal and new-born outcomes in the context of universal screening.

\section{METHODS}

This single-centre, retrospective observational study reviewed historical, routinely collected data of antenatal women in Health Clinic Seremban over one year in 2018. Antenatal care is universally accessible to all pregnant women in Malaysia. This clinic covers an estimated population of 250,000. Annually it provides antenatal care for approximately 1000 to 2000 women. In 2018 total attendance was 1791. Women diagnosed with GDM during routine antenatal care were managed according to the GDM Clinical Practice guidelines (GDM CPG) developed by the Ministry of Health Malaysia which is practised across clinics in Malaysia ${ }^{6}$.

The universal screening approach was adopted in this clinic. All antenatal women were screened using a 75-gram oral glucose tolerance test (OGTT) done at booking and if result was normal it will be repeated at 24-28 weeks of gestation. Women with abnormal fasting plasma glucose (FPG): $\geqslant 5.1 \mathrm{mmol} / \mathrm{L}$, or 2-hours postprandial (2 HPP) $\geqslant 7.8 \mathrm{mmol} / \mathrm{L}$ were diagnosed with GDM.

All women diagnosed with GDM who had no previous diagnosis of type 1 diabetes (T1DM) or type 2 diabetes (T2DM) were included in this study. The exclusion criteria included a previous diagnosis of T1DM and T2DM or had suffered a miscarriage or women who had consulted other clinics for their antenatal check-ups.

Data extracted from the antenatal records include personal, antenatal, and postnatal information. At booking, maternal age, body mass index (BMI), weight, parity, history of previous stillbirths and hypertension, abortion, and family history of diabetes were collected. Booking was defined as the measurement documented at the first contact at the health clinic. The total sample collected for the study was 987 after excluding for existing T2DM, miscarriage and abortion $(n=20)$ and those consulting other clinics.

Data was stratified according to risk factors of GDM to compare the performance of a selective screening approach for those with high risk, to that of universal screening in detecting GDM. Participants were categorized as high-risk for GDM based on the guidelines recommended by the GDM CPG. 


\section{Statistical Analysis}

Data was processed using the IBM SPSS Statistical Software version 26. Significant associations between categorical variables were analysed using the chi-square test or Fisher's exact test as appropriate. Independent tests were used to identify differences in continuous variables between mothers with and without GDM diagnosis. Logistic regression was used to quantify the relationship between identified risk factors and the likelihood of having GDM. The risk factors used in the logistic regression model included age, BMI, number of abortions and gravida as continuous variables while ethnicity, family history of diabetes and history of GDM were coded as categorical variables. Statistical significance was set at $\mathrm{p}<0.05$.

\section{Ethical consideration}

This study has been approved by the International Medical University Joint Committee on Research and Ethics PID: IMU 442/2019 and the National Medical Research Register NMRR:1992246217 (IIR).

\section{RESULTS}

Prevalence of risk factors for GDM in the cohort

A total of $246(24.9 \%)$ women were diagnosed with GDM from the analysed group $(n=987)$. Prevalence of the recognized risk factors associated with GDM in this cohort is listed in Table 1.

Table 1: Prevalence of risk factors for GDM $(n=987)$

\begin{tabular}{ll}
\hline Risk factor & Prevalence N (\%) \\
\hline Age $\geq 25$ years & $771(78.1 \%)$ \\
BMI> 27 at booking visit & $633(64.1 \%)$ \\
Family history of diabetes & $299(30.3 \%)$ \\
History of abortion & $226(22.9 \%)$ \\
History of GDM & $59(6.0 \%)$ \\
Hypertension & $19(1.9 \%)$ \\
\hline
\end{tabular}

Note: $B M I=$ Body mass index; $G D M=$ Gestational diabetes mellitus, Hypertension = Essential and Pregnancyinduced

An age at or over 25 years and being overweight were the most common risk factor in this cohort, followed by a family history of diabetes and a history of abortion. An existing history of GDM and hypertension was less prevalent in this cohort of pregnant women.
The distribution of risk factors among the study participants stratified by age is shown in Table 2 . Fifty percent of the women aged $<25$ years and $33.5 \%$ of women $\geq 25$ years had no common risk factors for GDM.

Table 2: Total number of risk factors for GDM stratified by age

\begin{tabular}{lcccc}
\hline \multicolumn{1}{c}{ Maternal age } & \multicolumn{2}{c}{ Age $<25$ years } & \multicolumn{2}{c}{ Age $\geq 25$ years } \\
\hline No of risk factors & Frequency & Percentage & Frequency & Percentage \\
\hline 0 & 108 & 50.0 & 258 & 33.5 \\
1 & 67 & 31.0 & 291 & 37.7 \\
2 & 36 & 16.7 & 161 & 20.9 \\
3 & 4 & 1.9 & 55 & 7.1 \\
4 & 1 & 0.5 & 6 & 0.8 \\
\hline Total & 216 & 100.0 & 771 & 100.0 \\
\hline
\end{tabular}


Table 3: Comparison of universal versus selective

\begin{tabular}{|c|c|c|c|c|c|c|c|}
\hline & \multicolumn{7}{|c|}{ Selective Screening } \\
\hline & & \multicolumn{2}{|c|}{ No GDM } & \multicolumn{2}{|c|}{ GDM } & \multicolumn{2}{|c|}{ Total } \\
\hline & & $\mathrm{n}$ & $\%$ & $\mathrm{n}$ & $\%$ & $\mathrm{n}$ & $\%$ \\
\hline \multirow[t]{3}{*}{ Universal screening } & No GDM & 312 & 42.1 & 429 & 57.9 & 741 & 75.1 \\
\hline & GDM & 54 & 22.0 & 192 & 78.0 & 246 & 24.9 \\
\hline & Total & 366 & 37.1 & 621 & 62.9 & 987 & 100 \\
\hline
\end{tabular}

Note: GDM = Gestational diabetes mellitus

\section{Evaluation of effectiveness of universal screening vs hypothetical selective screening.}

A comparison of GDM diagnosed using the universal vs hypothetical selective screening strategies is presented in Table 3.

Some data on risk factors such as a history of macrosomia, glycosuria and use of corticosteroids were not available. In the absence of these data, however, it was found that selective screening using traditional risk factors to identify pregnant women at risk for GDM would have missed 54 (22\%) women who received a positive diagnosis when universal screening was used. Of the $54,40(74 \%)$ of these women were $\geq 25$ years of age and selective screening would have conducted the test only at 24 to 28 weeks and may have delayed treatment. The $14(26 \%)$ who were < 25 years old would likely have missed screening and been subjected to higher risks of GDM and its complications.

\section{Maternal and New-born Characteristics}

\section{Maternal}

The characteristics of the maternal and new-born are shown in Table 4a and 4b.
Women who had a diagnosis of GDM were significantly older, had higher BMI, reported higher gravida, had experienced a higher number of abortions, delivered earlier and were less likely to have normal deliveries. Others and Indian ethnicity were seen to have a higher proportion with GDM diagnosis. Women with GDM also had a higher prevalence of a family history of T2DM and history of GDM. The maternal health indicators for blood glucose levels and blood pressure were overall well controlled in this cohort. Moreover, there were no significant differences in the reported parity or blood pressure among the women with and without GDM.

\section{New-born}

The general characteristics of new-born to mothers diagnosed with and without GDM are shown in Table 4b. There was no significant difference in the birth weight or the Apgar scores at 1 and 5 minutes of the children born to the mother with and without GDM in this cohort. No stillbirths were recorded. Among the 987 live births documented in this cohort, $12.5 \%$ (123) were underweight $(<2.5 \mathrm{~kg}), 86.65 \%(855)$ were of normal weight and $0.9 \%$ (9) were overweight (> $3.99 \mathrm{~kg})$.

Table 4a: Comparison of Characteristics of Maternal and New-born with or without GDM

\begin{tabular}{lllc}
\hline & $\begin{array}{l}\text { GDM } \\
(\mathbf{n}=\mathbf{2 4 6})\end{array}$ & $\begin{array}{l}\text { Without GDM } \\
(\mathbf{n}=\mathbf{7 4 1})\end{array}$ & P-Value \\
\hline Maternal Characteristics & & & \\
\hline Age in years & $31 \pm 5$ & $29 \pm 5$ & $<0.001$ \\
Ethnic groups & & & 0.003 \\
$\quad$ Malay n (\%) & $100(41 \%)$ & $375(51 \%)$ & \\
Chinese n (\%) & $58(24 \%)$ & $187(25 \%)$ & \\
Indians n (\%) & $73(30 \%)$ & $141(19 \%)$ & \\
Others n (\%) & $15(6 \%)$ & $38(5 \%)$ &
\end{tabular}


Table 4b: Comparison of Characteristics of Maternal and New-born with or without GDM

\begin{tabular}{lllr}
\hline & $\begin{array}{l}\text { GDM } \\
(\mathrm{n}=246)\end{array}$ & $\begin{array}{l}\text { Without GDM } \\
(\mathrm{n}=741)\end{array}$ & P-Value \\
\hline Maternal Characteristics & & & \\
\hline $\begin{array}{l}\text { Obstetric History } \\
\text { Gravida }\end{array}$ & $2(2)$ & $2(2)$ & 0.030 \\
Parity & $1(2)$ & $1(2)$ & 0.227 \\
No of Abortions & $0(1)$ & $0(0)$ & 0.001 \\
& & & \\
Weeks of pregnancy at delivery & $38(2)$ & $38(2)$ & 0.001 \\
Methods of delivery & & & 0.002 \\
Normal SVD (\%) & $130(53 \%)$ & $477(64 \%)$ & \\
LSCS (\%) & $113(46 \%)$ & $249(34 \%)$ & \\
Instrumental delivery (\%) & $3(1 \%)$ & $15(2 \%)$ & $<$ \\
Medical history and clinical data (\%) & & & 0.001 \\
Presence of family history of diabetes n (\%) & $116(47 \%)$ & $183(25 \%)$ & $<0.001$ \\
History of GDM n (\%) & $40(16 \%)$ & $19(3 \%)$ & $<0.001$ \\
BMl kg/m² (Mean \pm SD) & $27.2 \pm 5.7$ & $25.1 \pm 5.0$ & $<0.001$ \\
Fasting Blood Glucose mmol/L & $5.1 \pm 0.8$ & $4.3 \pm 0.3$ & 0.001 \\
2hr Postprandial Blood Glucose mmol/L & $8.1 \pm 1.7$ & $5.6 \pm 1.0$ & 0.633 \\
Systolic BP mmHg & $110 \pm 9$ & $110 \pm 9$ & $70 \pm 7$ \\
Diastolic BP mmHg & $70 \pm 8$ & & 0.328
\end{tabular}

T2DM diagnosis at 6 weeks postpartum $\mathrm{n}(\%)$

$20 / 226(8.1 \%) \quad 0 / 741(0 \%) \quad<0.001$

New-born Characteristics

Baby birth weight (Kg)

$2.94 \pm 0.46 \quad 2.96 \pm 0.44 \quad 0.279$

Underweight (2.49 kg or less) $\mathrm{n}(\%)$

$36(14.6 \%) \quad 87(11.7 \%) \quad 0.184$

Normal $(2.5-3.99 \mathrm{~kg}) \mathrm{n}(\%)$

$206(83.7 \%) \quad 649(87.6 \%)$

Overweight (4 kg or more) $\mathrm{n}(\%)$

$4(1.6 \%) \quad 5(0.7 \%)$

Apgar 1-minute (Median (IQR))

9(0)

9(0)

0.641

Apgar 5-minutes (Median (IQR))

9(0)

$9(0)$

0.607

Note: $G D M=$ Gestational diabetes mellitus; SVD = Spontaneous vaginal delivery; $L S C S$ = Lower segment caesarean section; $B M I=$ Body mass index; $B P=$ Blood pressure; T2DM = Type 2 diabetes mellitus profile. All continuous measures presented as (Mean $\pm S D$ ) unless indicated otherwise.

Factors associated with GDM in the Study Cohort

The logistic regression model including the predictors shown in Table 5, was satisfactory, as assessed by a Hosmer Lemeshow test ( $p=$ 0.216). Age, BMI, gravida, family history of T2DM and a positive history of GDM were all significant predictors of GDM diagnosis in the current pregnancy 
Table 5: Logistic regression model for GDM diagnosis in the current pregnancy

\begin{tabular}{|c|c|c|c|c|}
\hline \multirow[t]{2}{*}{$\begin{array}{l}\text { Maternal } \\
\text { characteristics }\end{array}$} & \multirow[t]{2}{*}{ OR } & \multicolumn{2}{|c|}{$95 \% \mathrm{Cl}$ for OR } & \multirow[t]{2}{*}{$\mathrm{P}$-value } \\
\hline & & Lower & Upper & \\
\hline Age & 1.081 & 1.043 & 1.121 & $<0.001$ \\
\hline Race (ethnicity) & & & & 0.030 \\
\hline Malay (Ref category) & 1 & & & \\
\hline Chinese & 1.383 & 0.922 & 2.074 & 0.117 \\
\hline Indians & 1.530 & 1.028 & 2.277 & 0.036 \\
\hline Others & 2.320 & 1.181 & 4.559 & 0.015 \\
\hline BMI & 1.066 & 1.034 & 1.099 & $<0.001$ \\
\hline Gravida & 0.797 & 0.691 & 0.920 & 0.002 \\
\hline No of abortions & 1.487 & 1.134 & 1.949 & 1.487 \\
\hline FHDM & 2.218 & 1.594 & 3.085 & 2.218 \\
\hline History of GDM & 5.661 & 3.053 & 10.497 & $<0.001$ \\
\hline
\end{tabular}

Malay ethnicity had significantly lower odds for GDM diagnosis compared to Indians and "Others" (those not belonging to Malay, Chinese or Indian ethnicities). In the logistic regression model, the Indian and other ethnic women had 1.5 and 2.3 times the odds for GDM respectively as compared to Malays. Having a family history of diabetes mellitus increased the odds for GDM by approximately 2 folds and those with a previous history of GDM by 6 folds.

In this model, every year increase in maternal age increased the odds for GDM diagnosis by $8 \%$ and every unit increase in $B M I$ increased the odds for GDM by approximately $7 \%$. Also, each previous abortion increased the odds for GDM diagnosis by approximately $50 \%$.

\section{DISCUSSION}

The diagnostic criteria for GDM adopted in the study site is almost similar to that of the IADSPG. The IADPSG diagnostic criteria for FPG, 1 HPP \& 2 HPP (with a $75 \mathrm{~g}$ OGTT) are: $5.1 \mathrm{mmol} / \mathrm{L}$, $10 \mathrm{mmol} / \mathrm{L}$ or, $8.5 \mathrm{mmol} / \mathrm{L}$ respectively ${ }^{13,14}$. As compared to that of the Malaysian Clinical Practice Guidelines with a slightly lower diagnostic value of FPG $5.1 \mathrm{mmol} / \mathrm{L}$ or $2 \mathrm{HPP}$ more than $7.8 \mathrm{mmol} / \mathrm{L}$ with a $75 \mathrm{~g}$ OGTT ${ }^{6}$.

With the lower diagnostic values of FPG and 2 HPP, the observed GDM prevalence of $24.9 \%$ in this study falls closer to the higher prevalence amongst those previously reported in Malaysia ${ }^{15-}$ 17. This prevalence is also relatively higher compared to the prevalence in several systematic reviews for Asia, Sub-Saharan and Middle Eastern regions reporting only between $3 \%$ to $12.2 \%{ }^{18-20}$. While the observed prevalence of GDM in this cohort may be alarming, it comes as no surprise. Negeri Sembilan, the state where this clinic is located, is with the highest prevalence of diabetes amongst adults in $2019^{21}$.

We found ethnicity to be independently associated with the prevalence of GDM. These findings reiterated the results of Chew et al. and Hussein who reported that the prevalence of GDM was highest amongst the Malaysian Indians, followed by Malays and Chinese ${ }^{22,23}$. Chong et al, however found that GDM in Singapore was most prevalent amongst the Chinese, followed by Malays and Indians ${ }^{24}$. The possible cumulative effect of acculturation on diabetes risk as well as environmental exposure may vary by ethnic group depending on the prevalence of diabetes in the host country and location of residence ${ }^{25}$. It is worth noting that within Asian ethnic groups, there are disparities in the risk of GDM by raceethnicity and country of birth, even though in the case here, both Singaporean and Malaysian mothers, have good access to healthcare.

In Li's systematic review, the dose-response analysis showed that GDM risk exhibited a linear relationship with maternal age. For each oneyear increase in maternal age from 18 years, GDM risk for the overall population, Asian population, and the European population increased by $7.90 \%$, $12.74 \%$, and $6.52 \%$, respectively ${ }^{26}$. In our study, the prevalence of GDM progressively increased across maternal age groups. The highest incidence of GDM was in the 30 to 34 years $(43.1 \%)$ 
age range. However, for every year older the mother is, the odds of diagnosis increased by $8 \%$.

BMI has been strongly associated with GDM. A single unit increase in BMl dictated an increase in the odds for GDM by $7 \%$ amongst the mothers in this study. This concurs with the meta-analysis done by Chu et al that determined that the risk of GDM was two, four and eight times more likely among overweight, obese, and severely obese women respectively, in comparison to pregnant women with normal weights ${ }^{27}$.

History of abortion is noted to have a significant relationship with GDM. Moosazadeh et al, found that the total odds ratio of spontaneous abortion among pregnant women with GDM was 3.01 times more than that in pregnant women without GDM (95\% Cl: 2.38 to 3.82$)^{28}$. This study found that a previous history of GDM and abortions increased risks of GDM for each reported abortion in the mother. It is highly likely that women with prior GDM are more likely to have experienced abortions and have higher risks for developing GDM in their subsequent pregnancies.

The maternal and new-born outcomes with GDM have shown favourable sequelae in this study. There were no significant differences observed in the blood pressure of GDM and non-GDM patients. The same was noted for the weight and Apgar score of babies. Further analysis also revealed that none of the 54 women who would have been missed by selective screening, had babies with macrosomia nor developed T2DM at 6 weeks postpartum. They could have benefited from close monitoring and management that has been practised in this health clinic. Therefore, an early universal screening as adopted in this site may be useful in improving maternal and foetal outcomes through early intervention.

Selective screening for GDM in Malaysia may be a more cost-effective approach in resourcestrained circumstances. However, considering recent evidence on the availability and benefits of interventions, there are growing movements towards universal screening. As Idris et al pointed out, universal screening dictated a higher sensitivity and specificity compared to selective screening ${ }^{15}$. Selective screening based on maternal characteristics of age, booking BMI, weight, and hypertension as a risk for GDM among Malaysians is considered inappropriate especially with regards to reducing maternal and foetal complications $^{29}$. Risk factors used in high-risk screening do not sufficiently predict GDM risk and have failed to detect half the GDM cases in Asian women ${ }^{24}$. Our findings were also in favour of universal screening since 54 or $22 \%$ extra participants were picked up. Although 40 of the 54 of the antenatal mothers would have been diagnosed with GDM at a later date, it would, however, have delayed management and caused an increased risk of adverse neonatal outcomes. The remaining 14 would not have been screened otherwise if selective screening was adopted.

Our findings have important implications for GDM screening in Malaysia. While this study may be limited to in one of the many Ministry of Health clinics' in Malaysia, the practice that is adopted may be replicable to all similar health clinics. The ease of implementation to all mothers as reported in this clinic would be a better option, rather than screening each mother for the respective risk factors that have been listed and identified in the GDM CPG, avoiding a potential $22 \%$ of delayed diagnosis. Although the cost for screening and treatment would increase by implementing universal screening per clinic, there will however be potential savings from economies of scale that can be benefitted from if done nationally. With potentially $22 \%$ of GDM mothers undetected extrapolated to the estimated average total of 501,945 in 2018 pregnancies ${ }^{30}$, that would come to about 25,000 mothers annually possibly undetected during the early phase of their antenatal care. With the high prevalence of T2DM and earnest efforts of Malaysian's $\mathrm{MOH}$ to identify pre-diabetics and diabetics through opportunistic public health clinic outpatient visits, the investment in performing universal screening for GDM is in-line with the national agenda in which the resources have been set aside dedicated for this initiative.

The authors acknowledged a few limitations of this study which did not involve a control site where selective screening was carried out. Therefore, adverse outcomes experienced by mothers and infants from resultant undetected and untreated GDM were not evaluated. The study has also not addressed the costeffectiveness of the provision of universal screening. However, the study does provide information with a strong rationale for future research on the cost-benefit analysis of the universal screening strategies of GDM in Malaysia.

\section{CONCLUSIONS}

This study highlights the high prevalence of GDM especially among older women, those with higher $\mathrm{BMI}$, a family history of diabetes or belonging to Indian and other ethnicities. 
Universal screening picked up an additional 22\% of mothers who would otherwise have been missed by selective screening, which would have impacted early management.

\section{ACKNOWLEDGEMENTS}

The authors are thankful to the Director-General of Health for providing permission to publish this study. Special mention to all the health staff who have assisted with the collection of the data in the health clinic.

\section{Funding:}

This work was supported by the International Medical University Joint-Committee on Research \& Ethics, Project ID No: IMU442/2019

\section{Competing interest:}

None

\section{REFERENCES}

1. Cho NH, Shaw JE, Karuranga $S$, Huang $Y$, da Rocha Fernandes JD, Ohlrogge AW, et al. IDF Diabetes Atlas: Global estimates of diabetes prevalence for 2017 and projections for 2045. Diabetes Res Clin Pract. 2018;138:271-81.

2. Bener A, Saleh NM, Al-Hamaq A. Prevalence of gestational diabetes and associated maternal and neonatal complications in a fast-developing community: Global comparisons. Int J Womens Health. 2011;3:367-73.

3. Eades CE, Styles M, Leese GP, Cheyne H, Evans JMM. Progression from gestational diabetes to type 2 diabetes in one region of Scotland: An observational follow-up study. BMC Pregnancy Childbirth. 2015;3(15):11.

4. Metzger BE, Contreras M, Sacks DA, Watson W, Dooley SL, Foderaro M, Niznik C, Bjaloncik J, Catalano PM, Dierker L, Fox S. Hyperglycemia and adverse pregnancy outcomes. New England journal of medicine. 2008 May 8;358(19):1991-2002.

5. Kendrick JM. Screening and diagnosing gestational diabetes mellitus revisited: implications from HAPO. The Journal of perinatal \& neonatal nursing. $2011 \mathrm{Jul}$ $1 ; 25(3): 226-32$.

6. Ministry of Health $M$. Management of diabetes in pregnancy [Internet]. 2017 [cited 2020 Sep 1]. p. 1-8. Available from: https://www.moh.gov.my/moh/resources/ Penerbitan/CPG/Endocrine/1b.pdf
7. Carr SR. Screening for gestational diabetes mellitus: A perspective in 1998. Diabetes Care. 1998;(Suppl 2):B14-8.

8. Lindsay RS, Mackin ST, Nelson SM. Gestational diabetes mellitus-right person, right treatment, right time? BMC Med. 2017;15(163).

9. Arora D, Rajin D, Sangthong S, Leelaporn W, Sangratanathongchai J. Universal screening of gestational diabetes mellitus: Prevalence and diagnostic value of clinical risk factors. J Med Assoc Thail. 2013;96(3):266-71.

10. Tieu J, Mcphee AJ, Crowther CA, Middleton $P$. Screening and subsequent management for gestational diabetes for improving maternal and infant health. Cochrane Database Syst Rev. 2014;11(2):CD007222.

11. Hod M, Pretty M, Mahmood T. Joint position statement on universal screening for GDM in Europe by FIGO, EBCOG and EAPM. Eur J Obstet Gynecol Reprod Biol. 2018;(228):32930.

12. Hod M, Kapur A, Sacks DA, Hadar E, Agarwal $M$, Di Renzo GC, et al. The International Federation of Gynecology and Obstetrics (FIGO) Initiative on gestational diabetes mellitus: A pragmatic guide for diagnosis, management, and care. In: International Journal of Gynecology and Obstetrics. 2015. p. S173-211.

13. International Association of Diabetes and Pregnancy Study Groups Consensus Panel. International Association of Diabetes and Pregnancy Study Groups Recommendations on the Diagnosis and Classification of Hyperglycemia in Pregnancy. Diabetes care 2010, 33;3 (676-682_. Available from: https: //www.ncbi.nlm.nih.gov/pmc/article s/PMC2827530/pdf/zdc676.pdf

14. Lapolla, A., Chilelli, N. C., \& Dalfrà, M. G. (2011). New IADPSG recommendations: impact on care for gestational diabetes. Diabetes Management, 1(5), 497.

15. Idris $\mathrm{N}$, Che Hatikah $\mathrm{CH}$, Murizah $\mathrm{MZ}$, Rushdan MN. Universal versus selective screening for detection of gestational diabetes mellitus in a Malaysian population. Malaysian Fam Physician. 2009;4(2-3):83-7.

16. Subramaniam L, Bukhary binti Ismail Bukhary Md N, Kesihatan Bangi K, Kesihatan 
Hulu langat Tan Siow Foon MBBs P, Klinik Kesihatan Pelabuhan Klang Mm, Kesihatan daerah Klang Zienna Zufida $P$, et al. Gestational diabetes mellitus: The prevalence, associated factors and foetomaternal outcome of women attending antenatal care. Malaysian Fam Physician. 2017;12(2):9-17.

17. Shamsuddin K, Mahdy ZA, Rafiaah IS, Jamil $M A$, Rahimah MD. Risk factor screening for abnormal glucose tolerance in pregnancy. Int J Gynecol Obstet. 2001;75(1):27-32.

18. Badakhsh $M$, Daneshi $F$, Abavisani $M$, Rafiemanesh $\mathrm{H}$, Bouya $S$, Sheyback $M$, et al. Prevalence of gestational diabetes mellitus in Eastern Mediterranean region: a systematic review and meta-analysis. Endocrine. 2019;65:505-14.

19. Natamba BK, Namara AA, Nyirenda MJ. Burden, risk factors and maternal and offspring outcomes of gestational diabetes mellitus (GDM) in sub-Saharan Africa (SSA): a systematic review and meta-analysis. BMC Pregnancy Childbirth. 2019;19(450).

20. Nguyen CL, Pham NM, Binns CW, Van Duong $D$, Lee AH. Prevalence of gestational diabetes mellitus in eastern and southeastern Asia: A systematic review and meta-analysis. J Diabetes Res. 2018;6536974.

21. Abd Kadir, Ghani AAA, Rahman AB, Zainuddin AA, Jai AN, Chandran A. Institute for Public Health: National Health and Morbidity Survey 2015 (NHMS 2015). Vol. II: Non-Communicable Diseases, Risk Factors \& Other Health Problems. Kuala Lumpur: Min of Health Malaysia 2015. Acta Obstetrica et Gynaecologica Japonica. 2015. 15 p.

22. Chew WF, Rokiah P, Chan SP, Chee WSS, Lee LF, Chan YM. Prevalence of glucose intolerance, and associated antenatal and historical risk factors among Malaysian women with a history of gestational diabetes mellitus. Singapore Med J. 2012;53(12):81420.

23 Hussein Z, Taher SW, Gilcharan Singh HK,
Chee Siew Swee W. Diabetes Care in Malaysia: Problems, New Models, and Solutions. Ann Glob Heal. 2015;81(6):851-62.

24 Chong YS, Cai S, Lin H, Soh SE, Lee YS, Leow MKS, et al. Ethnic differences translate to inadequacy of high-risk screening for gestational diabetes mellitus in an Asian population: A cohort study. BMC Pregnancy Childbirth. 2014;14(345).

25 Hedderson MM, Darbinian JA, Ferrara A. Disparities in the risk of gestational diabetes by race-ethnicity and country of birth. Paediatr Perinat Epidemiol. 2010;24(5):4418.

26. Li Y, Ren X, He L, Li J, Zhang S, Chen W. Maternal age and the risk of gestational diabetes mellitus: A systematic review and meta-analysis of over 120 million participants. Diabetes Res Clin Pract. 2020;(162):108044.

27. Chu SY, Callaghan WM, Kim SY, Schmid CH, Lau J, England LJ, et al. Maternal obesity and risk of gestational diabetes mellitus. Diabetes Care. 2007;30(8):2070-6.

28. Moosazadeh M, Banakar M, Behbahani D, Akbari $\mathrm{M}$, Dabbaghmanesh $\mathrm{MH}$, Mohamadkhani $M$, et al. Association between gestational diabetes mellitus and spontaneous abortion: A systematic review and meta-analysis. J Maz Univ Med Sci. 2017;27(155):187-19.

29. Ganeshan M, Soelar SA, Karalasingam SD, Bujang MA, Jeganathan $R$, Suharjono $H$. Effectiveness of selective risk based screening for Gestational Diabetes (GDM) in Malaysia: A retrospective cohort study based on the National Obstetric Registry (NOR) of Malaysia. Med J Malaysia. 2017;72(1):46-9.

30. Pejabat Ketua Perangkawan. Siaran Akhbar: Perangkaan Penting, Malaysia, 2014 [Internet]. Jabatan Perangkaan Malaysia. Kuala Lumpur; 2015. Available from: https: / / www.dosm.gov.my/v1/index.php?r =column/pdfPrev\&id=STg1 NEgvdFlaZldlc0JF NIRQczB6dz09 